\title{
3 Research Square \\ The effect of Self-Rated Health in Pregnancy on the type of delivery in Bandar Abbas pregnancy cohort, 2016-2018
}

\section{Kourosh Holakouie-Naieni}

tehran university of medical sciences, Dep of Epidemiology and Biostatistics and Bandar Abbas Health Reseacher Station, WHO Reginal Malaria Training center

Shahrzad Nematollahi

Shaheed Beheshti University of Medical Sciences

Abdul-Hussain Madani

Hormozgan University of Medical Sciences

Hossein Moameri ( $\nabla$ hossein_moameri67@yahoo.com )

Tehran University of Medical Sciences Department of Epidemiology and Biostatistics https://orcid.org/0000-0003-0505-4473

Research article

Keywords: Self-Rated Health, Cesarean section, Prospective cohort study

Posted Date: October 10th, 2019

DOl: https://doi.org/10.21203/rs.2.15895/v1

License: (c) (1) This work is licensed under a Creative Commons Attribution 4.0 International License. Read Full License 


\section{Abstract}

Background Self-rated health in pregnancy can be a predictor of adverse childbirth outcomes and maternal health problems. The aim of the present study was to investigate the effect of maternal selfrated health on the type of delivery in Bandar Abbas pregnancy cohort.

Methods This study used data of 247 mothers registered in a prospective cohort study on pregnant women in the suburbs of Bandar Abbas city, South of Iran. Self-rated health of mothers in pregnancy was measured by the answer to the question: "How do you evaluate your health in general?" The study outcome defined as having cesarean section measured at the second visit during postpartum period. The relative risk (RR) and 95\% confidence interval $(\mathrm{Cl})$ was calculated using Cox regression models.

Results The prevalence of bad/poor, good/excellent Self-rated health and cesarean section was 19.3\% $(n=42), 80.97 \%(n=200)$ and $40 \%$, respectively. Compared to good self-rated health, the risk of cesarean section was $78 \%$ higher $(\mathrm{RR}=1.78,95 \% \mathrm{Cl} 1.32-2.4)$ in mothers with bad self-rated health. The risk of elective cesarean section and emergency cesarean section was $72 \%(\mathrm{RR}=1.72,95 \% \mathrm{Cl} 1.09-2.7)$ and $91 \%(R R=1.91,95 \% \mathrm{Cl} 1.04-3.48)$ higher in mothers with bad self-rated health, respectively.

Conclusion Our findings showed that self-rated health during pregnancy may effect cesarean section. Accordingly, the integration of screening for mental health morbidities into pregnancy health care packages are proposed.

\section{Introduction}

Cesarean Section (C-section) is one of the most common surgeries worldwide [1]. Although World Health Organization had reported the desirable level of C-section to be $10-15 \%$ in 1985 , it has increased significantly in the last few decades [2]. In Iran, C-section prevalence has increased from $16 \%$ in 1985 to $60 \%$ in 2013 [3]. According to recent systematic review in Iran, the prevalence of C-section is 48\% [4].This increase in C-section prevalence is followed by more inappropriate maternal and neonatal complications which requires more postpartum care and increases the costs and financial burdens for health system [5, 6].

Pregnancy complications, such as gestational diabetes [7], iron-deficiency anemia, preeclampsia [8], history of infertility, history of abortion [9] and a history of C-section [10] are factors influencing selection of cesarean delivery. In addition, some of the characteristics of the mother including mental health during pregnancy including depression and anxiety disorders during pregnancy [11], fear of childbirth [12], and self-rated health (SRH) are mentioned as factors influencing selection of this kind of delivery $[13,14]$.

$\mathrm{SRH}$ affects the type of delivery through some of factors during pregnancy or childbirth. Bad (poor) SRH has a direct relationship with hypertension, smoking during pregnancy [15], Intra-Uterine Growth Retardation [16,17], and preterm delivery, all of which are contributors of C-section [18]. On the other hand, some studies also reported lower rates of C-section in people with better self-rated health [13] Since 
$\mathrm{SRH}$ is an appropriate measure for evaluating mental health [19] that can affect C-section, and due to lack of native studies regarding the effects of SRH on pregnancy outcomes, this study aims to evaluate the effects of SRH of mothers during pregnancy on their delivery type through a population-based prospective cohort study in suburbs of Bandar Abbas during 2016 to 2018.

\section{Materials And Methods}

\section{Study design and Participants}

The present study used data from a population-based cohort study entitled:" A Population-based Prospective Study to Identify Contributors to Mother and Child Health in Suburban Communities". The project is being conducted by "Bandar Abbas health-Research station" affiliated to Tehran University of Medical Sciences (TUMS); and Hormozgan University of Medical Sciences Four visits are scheduled in pregnancy, one, six, and twelve months postpartum [20]. The reference population consists of pregnant women residing in the suburban areas of Bandar Abbas city with the socially and economically vulnerable neighborhoods. 1000 pregnant women is under recruitment by door to door sampling scheme. Details of the cohort protocol was published elsewhere [20]. By the time of the present study, the second visit of the cohort (during postpartum) was conducted on 283 singleton pregnancies, which yielded the following results: 14 (4.5\%) declined to participate, 12 (3.8\%) had migrated, and 10 (3.2\%) deliveries ended up with abortion. Therefore, 247 singleton deliveries were entered into the study.

\section{Ethics approval and consent to participate}

The Research Ethics Committee of "Ministry of Health and medical education" and "National Institute for Medical Research Development (NIMAD)" approved the protocol (Protocol Number: 943607 and ethical Number: IR.NIMAD.REC.1396.205). Moreover, ethical committee of school of public health of Tehran University of Medical Sciences (TUMS) with the code of 42933244/3246 approved this research. The mothers who agreed to participate were provided with written informed consent and were informed that they could drop out at any time during the study with no harm to themselves or their babies. Due to cultural situations in the area, verbal consent was sought from the husband, if necessary.

\section{Measures}

The main exposure of this research was $\mathrm{SRH}$ of mothers in pregnancy which was measured by the answer to the question: "How do you evaluate your health in general?" with responses on Likert scale (excellent, good, intermediate, bad, very bad) [19]. SRH was further divided into two categories of poor (intermediate, poor, and very poor) and good (very good and excellent) [21]. On the basis of prior research this variable was treated as categories $[17,19]$. Information about maternal self-rated health was collected through the first visit of the cohort during the first trimester. The study outcome was cesarean 
delivery, and elective and emergency C-section. Cesarean section was measured by self- report method. One week after delivery, mothers were asked using interviews or telephone call. The confounding variables were maternal age and education, pre-pregnancy body mass index (BMI), gestational age, preterm delivery, socio-economic status of the household, histories of C-section, abortion, and low birth weight infant. Maternal health status during pregnancy and using dietary supplements during pregnancy were also considered. Information about pre-pregnancy BMI was collected base on maternal health records health center. The household socioeconomic status was calculated using the principal component analysis (PCA) on nine household assets (personal car ownership, motorcycle, refrigerator, dishwasher, microwave, personal computer, vacuum cleaner, washing machine, color television). According to the median, socioeconomic status was divided into good (above the middle $(\leq 1)$ ) and poor (below the middle level $(0.999 \leq)$ ). Maternal mental health status during pregnancy was measured by DASS-21 scale [22]. The DASS is a clinical assessment that measures the three related states of depression, anxiety and stress. The validity and reliability of the DASS questionnaire in Iranian population has been confirmed before [23]. Mental impairment degree of the mother was defined by the total score of 33 or higher [22].

\section{Data analysis}

For the analyses, the relative risk was calculated using Cox regression models [24]. The log-binomial was proposed at the first step of the research development. At the analysis time; however, we realized that this model had converge problems due to some sparse data in level of the exposure of interest. Because of the sparse data problem, Cox-Regression model was used as an alternative. Typically, Cox regression is used for time-to-event data. To use Cox regression model for this particular situation, an artificial time variable was constructed where every subject has the same observation time and all events occur at the same time. With this assumption, the hazard ratio estimated by Cox regression approximates the relative risk. To investigate the univariable relationship between variables, univariable Cox regression models were used and then each variable with a significance level of less than 0.2 was included into the Cox regression multivariable model [25]. Accordingly, the confounders were previous $\mathrm{C}$-section, maternal body mass index, and socio-economic status for the cesarean section as a whole; previous C-section, history of preterm delivery, mother's body mass index during pregnancy, mother's education, and socio-economic status for elective $\mathrm{C}$-section, and maternal age and socio-economic status for emergency C-section. All the analyses were done by STATA v.14.2 and with a significance level of 5\%.

\section{Results}

247 pregnant mothers, aged 16 to 42 , participated in this study with the mean of 27.09 ( 5.37 ). Age category of 25-33 had the highest frequency. Most of the mothers were illiterate or had elementary education (29.96\%). Moreover, mothers with a good socioeconomic status had the highest frequency (Table 1). 
40.08\% of mothers had C-section, and $59.92 \%$ had vaginal delivery. Among all the deliveries, $24.29 \%$ were elective C-section, and 15.54\% were emergency C-section. Among 99 mothers who had C-section, $60.6 \%$ had experienced elective, and $39.4 \%$ had experienced emergency C-section. 16 mothers had pervious preterm delivery, among which $56.25 \%$ had C-section. 46 mothers had history of low weight birth, among which $65.22 \%$ had vaginal delivery. 200 mothers reported a good SRH, and 47 mothers reported a poor $\mathrm{SRH}$. The information about previous and current pregnancy of the mothers are listed in Table 2.

The Cox regression model indicated that after the adjustment of confounding variables, the risk of $\mathrm{C}$ section is 78\% higher in mothers with poor SRH (Adjusted Relative Riske (ARR) $=1.78,95 \%$ Confidence Interval (Cl): 1.32, 2.4) (Table 3).

According to the adjusted results of Cox regression model, the risk of elective C-section was $72 \%$ higher in mothers with poor SRH (ARR $=1.72,95 \% \mathrm{Cl}: 1.09,2.7)$ (Table 4).

The results of Cox regression model indicated that with adjustment of confounding variables, the risk of emergency C-section was 91\% higher in mothers with poor SRH (ARR $=1.91,95 \% \mathrm{Cl}$ : 1.04,3.48) (Table 5).

\section{Discussion}

The present study aimed to investigate the effects of SRH on the risk of cesarean delivery in 247 members of population-based prospective cohort group in Bandar Abbas city in South of Iran. The results indicated that $19 \%$ of the cohort subjects reported poor self-rated health. The prevalence of Cesarean section in our sample was estimated to be $40 \%$. This percentage appears to be higher than the estimated percentages in Saudi Arabia [26] and Iraq [27]; and lower than the estimated 48\% pooled prevalence reported by a systematic review study in Iran [28].

$\mathrm{SRH}$ is a valid predictor of health status and its reliability is increasingly approved. In comparison with other measures, SRH reflects the individual's perceptions regarding their own health status [29]. Our results indicated that mothers with poor SRH during pregnancy were exposed to $78 \%$ higher $\mathrm{C}$-section risk. This percentage is $72 \%$ for elective C-section and $91 \%$ for emergency C-section. The effect of SRH on cesarean delivery have been reported in a few studies $[13,30]$.

To be elaborated more, SRH has a direct relationship with some of the factors during pregnancy or childbirth, such as hypertension [31], tobacco smoking [15], low birth weight [16, 17] and preterm delivery [17], all of which are risk factors for choosing the type of delivery. According to the effects of low weight birth on selection of cesarean as the delivery type [32], this factor had probably emerged through mother's mental and health disorders during pregnancy. In the previous study on the cohort, we have shown that the incidence of low birth weight infants (i.e. birth weight below 2500 gram) was higher compared to other parts in Iran [33]. Therefore, it is presumed that low birth weight would effect on the type of delivery, especially choosing cesarean section. 
Our results also indicated that the risk of cesarean section was 2.5 times higher in mothers with previous caesarean experience. The effect of previous $\mathrm{C}$-section as a predictor of consequent $\mathrm{C}$-section have been proved in previous researches [32,34,35].

Poor SRH during pregnancy is been directly influenced by fear of delivery pain, recommendations of family members and physician for selecting cesarean as the delivery type, and concerns about changes in physical appearance [36, 37]. These factors are also influential in convincing the mother to select cesarean section. We did not have of the information on maternal mental health prior to conception, therefore, we cannot decide whether maternal poor mental health affects cesarean, or whether the history of C-section, lack of social support, and other factors decrease mother's mental health and lead her to select C-section as the delivery type [38].

According to the results, mothers with poor socio-economic status had $61 \%$ higher risk of C-section, $65 \%$ higher risk of elective $\mathrm{C}$-section, and $73 \%$ higher risk of emergency $\mathrm{C}$-section. Previous studies in Iran indicated that elective $\mathrm{C}$-section had a direct relationship with knowledge level of mothers regarding complications of delivery, fear of delivery, encouragements of the physician, recommendations of others, and socio-economic status of the family [37].

Although it is proven that maternal mental health during pregnancy affects delivery outcomes, applying the results in pregnancy health care packages is still in question. Emphasizing on the risks of C-section delivery is not enough for encouraging mothers to select vaginal delivery. Psychological counseling sessions during pregnancy is an appropriate opportunity for those mothers who are willing to select Csection. Therefore, regular screening programs to early diagnosis of mental health abnormalities with standard instruments (such as SCL-8 questionnaire) are highly recommended for pregnant mothers in order to make them aware of the risks of C-section [39].

Our study had some advantages and limitations. Its advantage was the nature of the study, which was prospectively conducted on the population level (population-based). On the other hand, the status of SRH is typically self-report. Therefore, it is possible that the prevalence of SRH would be higher with more false positives in comparison with other psychological diagnostic tests [36]. Moreover, some risk factors for the selection of delivery type was not available or statistically excluded from the analysis (such as the history of abortion, history of difficult delivery, history of chronic diseases) which can affect delivery process and maternal SRH.

\section{Conclusions}

Our study indicated that there is a significant relationship between SRH during pregnancy and the type of delivery. Therefore, mothers with poor SRH were more likely to have elective and emergency C-section. Moreover, risk of C-section in mothers with poor socio-economic status or mothers with previous Csection increased significantly. According to the results, analyzing and monitoring mother's mental health, especially during pregnancy, should be developed and receive more support. 


\section{Declarations}

Abbreviations: C-section: Cesarean Section, SRH: Self-rated health, BMI: Body Mass Index

\section{Acknowledgements}

We would like to forward our gratitude to the National Institute for Medical Research Development (NIMAD) for their financial support of this project. We also thank all residents in the study area, whose collaboration and patience is the milestone for the study progress.

\section{Authors' contributions}

$\mathrm{KH}$ conceptualized and supervised the study, SN coordinated research process, design, and data collection, HM conducted the interviews and undertook the analysis, EK developed the first draft of the manuscript. All authors contributed to subsequent drafts and all authors approved this version of the manuscript for publication.

\section{Competing interests}

The authors declare that they have no competing interests.

\section{Funding}

This research is funded by the Elite grant of National Institute for medical Research Development (NIMAD) with the code 943607 . The funders had no role in study design, data collection and analysis, decision to publish, or preparation of the manuscript.

\section{References}

1.Berghella V, Baxter JK, Chauhan SP. Evidence-based surgery for cesarean delivery. American Journal of obstetrics and gynecology 2005;193:1607-1617.

2.Betran A, Torloni M, Zhang J, Gülmezoglu A. WHO Statement on caesarean section rates. BJOG: An International Journal of Obstetrics \& Gynaecology 2016;123:667-670.

3.Dadipoor S, Madani A, Alavi A, Roozbeh N, Safari Moradabadi A. A survey of the growing trend of caesarian section in Iran and the world: a review article. Iranian Journal of Obstetrics, Gynecology and Infertility 2016;19:8-17.

4.Azami-Aghdash S, Ghojazadeh M, Dehdilani N, Mohammadi M. Prevalence and causes of cesarean section in Iran: systematic review and meta-analysis. Iranian journal of public health 2014;43:545. 
5.Liu T-C, Chen C-S, Lin H-C. Does elective caesarean section increase utilization of postpartum maternal medical care? Medical care 2008;46:440-443.

6.Souza J, Gülmezoglu A, Lumbiganon P, Laopaiboon M, Carroli G, Fawole B, et al. WHO Global Survey on Maternal and Perinatal Health Research Group. Caesarean section without medical indications is associated with an increased risk of adverse short-term maternal outcomes: the 2004-2008 WHO Global Survey on Maternal and Perinatal Health. BMC Med 2010;8:71.

7.Tolcher MC, Holbert MR, Weaver AL, McGree ME, Olson JE, El-Nashar SA, et al. Predicting cesarean delivery after induction of labor among nulliparous women at term. Obstetrics and gynecology 2015;126:1059.

8.Janoudi G, Kelly S, Yasseen A, Hamam H, Moretti F, Walker M. Factors associated with increased rates of caesarean section in women of advanced maternal age. Journal of Obstetrics and Gynaecology Canada 2015;37:517-526.

9.Rajabi A, Maharlouei N, Rezaianzadeh A, Rajaeefard A, Gholami A. Risk factors for C-section delivery and population attributable risk for C-section risk factors in Southwest of Iran: a prospective cohort study. Medical journal of the Islamic Republic of Iran 2015;29:294.

10.Ghadimi M, Rasouli M, Motahar S, Lajevardi Z, Imani A, Chobsaz A, et al. Affecting factors the choice of delivery and attitude of pregnant women admitted to the civil hospitals, the Social Security Organization in 2013. 2014

11.Bliddal M, Pottegård A, Kirkegaard H, Olsen J, Jørgensen JS, Sørensen TI, et al. Mental disorders in motherhood according to prepregnancy $\mathrm{BMI}$ and pregnancy-related weight changes-A Danish cohort study. Journal of affective disorders 2015;183:322-329.

12. Heimstad R, Dahloe R, Laache I, Skogvoll E, Schei B. Fear of childbirth and history of abuse: implications for pregnancy and delivery. Acta obstetricia et gynecologica Scandinavica 2006;85:435440 .

13.Stepanikova I, Kukla L, Svancara J. Predictive value of self-rated health in pregnancy for childbirth complications, adverse birth outcomes, and maternal health. International Journal of Gynecology \& Obstetrics 2016;135:56-60.

14.Yedid Sion M, Harlev A, Weintraub AY, Sergienko R, Sheiner E. Is antenatal depression associated with adverse obstetric and perinatal outcomes? The Journal of Maternal-Fetal \& Neonatal Medicine 2016;29:863-867.

15.Carty DC, Kruger DJ, Turner TM, Campbell B, DeLoney EH, Lewis EY. Racism, health status, and birth outcomes: results of a participatory community-based intervention and health survey. Journal of Urban Health 2011;88:84-97. 
16.Janjua NZ, Delzell E, Larson RR, Meleth S, Kristensen S, Kabagambe E, et al. Determinants of low birth weight in urban Pakistan. Public health nutrition 2009;12:789-798.

17.Teoli DA, Zullig KJ, Hendryx MS. Maternal fair/poor self-rated health and adverse infant birth outcomes. Health care for women international 2015;36:108-120.

18.Baron R, te Velde SJ, Heymans MW, Klomp T, Hutton EK, Brug J. The Relationships of Health Behaviour and Psychological Characteristics with Spontaneous Preterm Birth in Nulliparous Women. Maternal and child health journal 2017;21:873-882.

19.Nedjat S. Is Self-Rated Health a Good Indicator for Assessment of Population Health? A Review Article. Iranian Journal of Epidemiology 2015;10:89-96.

20.Holakouie-Naieni K, Nematollahi S, Mansournia MA, Shekari M, Agha-Molayi T, Alavi A, et al. A population-based prospective study to identify contributors to mother and child health in suburban communities: the cohort profile. Iranian journal of public health 2018;47:441.

21.Nedjat S, Hosseinpoor AR, Forouzanfar MH, Golestan B, Majdzadeh R. Decomposing socioeconomic inequality in self-rated health in Tehran. J Epidemiol Community Health 2012;66:495-500.

22.Antony MM, Bieling PJ, Cox BJ, Enns MW, Swinson RP. Psychometric properties of the 42-item and 21item versions of the Depression Anxiety Stress Scales in clinical groups and a community sample. Psychological assessment 1998;10:176.

23.Samani S, Jokar B. Validity and reliability of Short Form Depression Scale of Anxiety and Stress. Journal Of Social Sciences And Humanities Of Shiraz University 1386;52:65-78.

24.Barros AJ, Hirakata VN. Alternatives for logistic regression in cross-sectional studies: an empirical comparison of models that directly estimate the prevalence ratio. BMC medical research methodology 2003;3:21.

25.Greenland S, Pearce N. Statistical foundations for model-based adjustments. Annual review of public health 2015;36:89-108.

26.Ba'aqeel HS. Cesarean delivery rates in Saudi Arabia: a ten-year review. Annals of Saudi medicine 2009;29:179.

27.Al-Kubaisy W, Al-Rubaey M, Al-Naggar RA, Karim B, Noor NAM. Maternal obesity and its relation with the cesarean section: A hospital based cross sectional study in Iraq. BMC pregnancy and childbirth 2014;14:235.

28.Rafiei M, Naz MSG, Akbari M, Kiani F, Sayehmiri F, Sayehmiri K, et al. Prevalence, causes, and complications of cesarean delivery in Iran: A systematic review and metaanalysis. International Journal of Reproductive Biomedicine 2018;16 
29.Schnittker J, Bacak V. The increasing predictive validity of self-rated health. PloS one 2014;9:e84933.

30.Schytt E, Hildingsson I. Physical and emotional self-rated health among Swedish women and men during pregnancy and the first year of parenthood. Sexual \& reproductive healthcare 2011;2:57-64.

31.Ursua RA, Islam NS, Aguilar DE, Wyatt LC, Tandon SD, Abesamis-Mendoza N, et al. Predictors of hypertension among Filipino immigrants in the Northeast US. Journal of community health $2013 ; 38: 847-$ 855 .

32.Stivanello E, Rucci P, Lenzi J, Fantini MP. Determinants of cesarean delivery: a classification tree analysis. BMC pregnancy and childbirth 2014;14:215.

33.Nematollahi S, Mansournia MA, Foroushani AR, Mahmoodi M, Alavi A, Shekari M, et al. The effects of water-pipe smoking on birth weight: a population-based prospective cohort study in southern Iran. Epidemiology and health 2018;40

34.Giani U, Bruzzese D, Pugliese A, Saporito M, Triassi M. Risk factors analysis for elective caesarean section in Campania region (Italy). Epidemiologia e prevenzione 2011;35:101-110.

35.Qin C, Zhou M, Callaghan WM, Posner SF, Zhang J, Berg CJ, et al. Clinical indications and determinants of the rise of cesarean section in three hospitals in rural China. Maternal and child health journal 2012;16:1484-1490.

36. Olieman RM, Siemonsma F, Bartens MA, Garthus-Niegel S, Scheele F, Honig A. The effect of an elective cesarean section on maternal request on peripartum anxiety and depression in women with childbirth fear: a systematic review. BMC pregnancy and childbirth 2017;17:195.

37.Tavassoli A, Dizaji AZ, Kelari F. Social Factors affecting to Elective Cesarean In Iran. Bioethics and Health Law Journal (BHL) 2017;1:41-46.

38.Størksen HT, Garthus-Niegel S, Adams SS, Vangen S, Eberhard-Gran M. Fear of childbirth and elective caesarean section: a population-based study. BMC pregnancy and childbirth 2015;15:221.

39.Fink P, Ørnbøl E, Hansen MS, Søndergaard L, De Jonge P. Detecting mental disorders in general hospitals by the SCL-8 scale. Journal of Psychosomatic Research 2004;56:371-375.

\section{Tables}

Table 1: Demographic characteristics of the pregnant women in suburban of Bandar Abbas, 2017 


\begin{tabular}{|c|c|c|c|c|c|}
\hline \multirow[t]{2}{*}{ variable } & \multirow[t]{2}{*}{$\mathbf{N}(\%)$} & \multicolumn{3}{|c|}{ Type of delivery } & \multirow{2}{*}{$\begin{array}{l}\text { P- } \\
\text { value* }\end{array}$} \\
\hline & & $\begin{array}{c}\text { Elective C- } \\
\text { section N (\%) }\end{array}$ & $\begin{array}{l}\text { Emergency C- } \\
\text { section N (\%) }\end{array}$ & $\begin{array}{c}\text { Vaginal } \\
\mathbf{N}(\%)\end{array}$ & \\
\hline \multicolumn{6}{|c|}{ Maternal Age (years) } \\
\hline $16-24$ & $83(34.01)$ & $16(19.27)$ & $12(14.45)$ & $\begin{array}{c}55 \\
(66.26)\end{array}$ & \multirow[t]{3}{*}{0.27} \\
\hline $25-33$ & $131(52.63)$ & $36(27.48)$ & $19(14.50)$ & $\begin{array}{c}76 \\
(58.01)\end{array}$ & \\
\hline $34-42$ & $33(13.36)$ & $8(24.24)$ & $8(24.24)$ & $\begin{array}{c}17 \\
(51.52) \\
\end{array}$ & \\
\hline \multicolumn{6}{|l|}{${ }_{\text {BMI }}^{[1]}$} \\
\hline $18.5 \geq$ & $16(6.48)$ & $1(06.25)$ & $0(00.00)$ & $\begin{array}{c}15 \\
(93.75)\end{array}$ & \multirow[t]{4}{*}{$>0.01$} \\
\hline $18.5-25$ & 103(41.70) & $25(24.27)$ & $13(12.62)$ & $65(63.11)$ & \\
\hline $25-30$ & $91(36.84)$ & $21(23.07)$ & $19(20.87)$ & $51(56.04)$ & \\
\hline $30 \leq$ & $37(14.98)$ & 13(35.13) & $7(18.91)$ & $17(45.95)$ & \\
\hline \multicolumn{6}{|c|}{ Socioeconomic status } \\
\hline Low & $74(29.96)$ & $26(35.13)$ & $16(21.62)$ & $\begin{array}{c}32 \\
(43.24)\end{array}$ & \multirow[t]{2}{*}{$>0.01$} \\
\hline good & $\begin{array}{c}173 \\
(70.04)\end{array}$ & $34(19.65)$ & 23(13.29) & $\begin{array}{c}116 \\
(67.05) \\
\end{array}$ & \\
\hline \multicolumn{6}{|l|}{ Maternal Education } \\
\hline $\begin{array}{l}\text { illiterate / reading } \\
\text { and writing }\end{array}$ & $74(29.96)$ & $23(31.08)$ & $9(21.16)$ & $\begin{array}{c}42 \\
(56.76)\end{array}$ & \multirow[t]{4}{*}{0.18} \\
\hline $\begin{array}{l}\text { secondary } \\
\text { education }\end{array}$ & $63(25.51)$ & $10(15.87)$ & $11(17.46)$ & $42(67.66)$ & \\
\hline $\begin{array}{l}\text { high school/ } \\
\text { diploma }\end{array}$ & $68(27.53)$ & $14(20.58)$ & $10(14.70)$ & $\begin{array}{c}44 \\
(64.71)\end{array}$ & \\
\hline University & $42(17.00)$ & 13(30.95) & $9(21.42)$ & $\begin{array}{c}20 \\
(48.62)\end{array}$ & \\
\hline
\end{tabular}

${ }^{*}$ Chi-squared test

Table 2: Characteristics of previous and current pregnancy of the pregnant women suburban of Bandar Abbas, 2017 


\begin{tabular}{|c|c|c|c|c|c|}
\hline \multirow{2}{*}{\multicolumn{2}{|c|}{ variable }} & \multicolumn{3}{|c|}{ Type of delivery } & \multirow{2}{*}{$\begin{array}{l}\text { P- } \\
\text { value* }\end{array}$} \\
\hline & & $\begin{array}{c}\text { Elective C- } \\
\text { section N (\%) }\end{array}$ & $\begin{array}{l}\text { Emergency C- } \\
\text { section N (\%) }\end{array}$ & $\begin{array}{c}\text { Vaginal } \\
\mathbf{N}(\%)\end{array}$ & \\
\hline \multicolumn{6}{|c|}{ Maternal self-rated health } \\
\hline good & $200(80.97)$ & $43(21.50)$ & $27(13.50)$ & $130(65.00)$ & \multirow[t]{2}{*}{$>0.01$} \\
\hline bad & $47(19.03)$ & $17(36.17)$ & $12(25.53)$ & $18(38.30)$ & \\
\hline \multicolumn{6}{|c|}{ Mental disorder } \\
\hline Yes & 18(7.29) & $5(27.77)$ & $3(16.66)$ & $10(55.56)$ & \multirow[t]{2}{*}{0.69} \\
\hline No & $129(92.71)$ & $55(42.63)$ & $36(27.90)$ & $138(60.26)$ & \\
\hline \multicolumn{6}{|c|}{ Iron supplementation in recent pregnancy } \\
\hline Regular & $168(68.02)$ & $40(23.80)$ & $25(14.88)$ & 103(61.31) & \multirow[t]{2}{*}{0.51} \\
\hline Irregular & $79(31.98)$ & $20(25.31)$ & $14(17.72)$ & $45(56.96)$ & \\
\hline \multicolumn{6}{|c|}{ vitamin D supplementation in recent pregnancy } \\
\hline Regular & 167(67.61) & $42(25.14)$ & $29(17.36)$ & $96(57.49)$ & \multirow[t]{2}{*}{0.25} \\
\hline Irregular & $80(32.39)$ & $18(22.50)$ & $10(12.50)$ & $52(65.00)$ & \\
\hline \multicolumn{6}{|c|}{ History of C-section [2] } \\
\hline Yes & $29(11.74)$ & $24(82.75)$ & $1(03.44)$ & $4(13.79)$ & \multirow[t]{2}{*}{$>0.01$} \\
\hline No & 218(88.26) & $36(16.51)$ & $38(17.43)$ & 144(66.06) & \\
\hline \multicolumn{6}{|c|}{ history of preterm delivery } \\
\hline Yes & $16(6.48)$ & $6(37.50)$ & $3(18.75)$ & $7(43.75)$ & \multirow[b]{2}{*}{0.16} \\
\hline No & 231(93.52) & $57(24.67)$ & $35(15.15)$ & 139(58.87) & \\
\hline \multicolumn{6}{|c|}{ History of Abortion } \\
\hline Yes & $22(8.91)$ & $4(18.18)$ & $3(13.63)$ & $15(68.18)$ & \multirow[t]{2}{*}{0.40} \\
\hline No & $225(91.09)$ & $56(24.88)$ & $36(16.00)$ & 133(59.11) & \\
\hline
\end{tabular}

*Chi-squared test

Table 3: Unadjusted and adjusted results of Cox regression models for the effect of mental self-rated health during pregnancy on delivery type (C-section / vaginal) 


\begin{tabular}{|c|c|c|c|c|c|c|c|}
\hline \multirow[t]{2}{*}{ variables } & \multirow[t]{2}{*}{$\mathbf{N}$} & \multicolumn{3}{|c|}{ Univariable } & \multicolumn{3}{|c|}{ Multivariable } \\
\hline & & ative ris & $95 \%$ CI & P-value & Relative risk & $95 \%$ CI & P-value \\
\hline \multicolumn{8}{|c|}{ Maternal self-rated health } \\
\hline good & 200 & 1 & - & - & 1 & - & - \\
\hline bad & 47 & 1.76 & $1.31-2.36$ & $>0.01$ & 1.78 & $1.32-2.4$ & $>0.01$ \\
\hline \multicolumn{8}{|c|}{ History of C-section [3] } \\
\hline No & 218 & 1 & - & - & 1 & - & - \\
\hline Yes & 29 & 2.53 & $2.00-3.21$ & $>0.01$ & 2.46 & $1.88-3.25$ & $>0.01$ \\
\hline \multicolumn{8}{|c|}{ Maternal Age (years) } \\
\hline $16-24$ & 83 & 1 & - & - & 1 & - & - \\
\hline $25-33$ & 131 & 1.21 & $0.84-1.72$ & 0.31 & 1.02 & $0.70-1.41$ & 0.69 \\
\hline $34-42$ & 33 & 1.41 & $0.88-1.22$ & 0.14 & 1.05 & $0.64-1.71$ & 0.46 \\
\hline \multicolumn{8}{|l|}{ BMI $^{[4]}$} \\
\hline $18.5 \geq$ & 16 & 1 & - & - & 1 & - & - \\
\hline $18.5-25$ & 103 & 5.91 & $0.86-40.19$ & 0.07 & 3.41 & $0.63-28.95$ & 0.12 \\
\hline $25-30$ & 91 & 7.03 & $1.03-47.76$ & 0.04 & 5.18 & $0.77-34.57$ & 0.08 \\
\hline $30 \leq$ & 37 & 8.64 & $1.26-59.27$ & 0.02 & 6.15 & $0.90-41.85$ & 0.05 \\
\hline \multicolumn{8}{|c|}{ Socioeconomic status } \\
\hline good & 173 & 1 & - & - & 1 & - & - \\
\hline low & 74 & 1.72 & $1.15-2.56$ & $>0.01$ & 1.61 & $1.17-2.22$ & $>0.01$ \\
\hline
\end{tabular}

Table 4: Unadjusted and adjusted results of Cox regression models for the effect of mental self-rated health during pregnancy on delivery type (Elective C-section / delivery other) 


\begin{tabular}{|c|c|c|c|c|c|c|c|}
\hline \multirow[t]{2}{*}{ variables } & \multirow[t]{2}{*}{$\mathbf{N}$} & \multicolumn{3}{|c|}{ Univariable } & \multicolumn{3}{|c|}{ Multivariable } \\
\hline & & $\begin{array}{l}\text { Relative } \\
\text { risk }\end{array}$ & 95\% CI & $\begin{array}{l}\text { P- } \\
\text { value }\end{array}$ & $\begin{array}{l}\text { Relative } \\
\text { risk }\end{array}$ & $95 \% \mathrm{CI}$ & $\begin{array}{l}\text { P- } \\
\text { value }\end{array}$ \\
\hline \multicolumn{8}{|c|}{ Maternal self-rated health } \\
\hline good & 43 & 1 & - & - & 1 & - & - \\
\hline bad & 17 & 1.67 & $\begin{array}{l}1.31- \\
2.36\end{array}$ & 0.02 & 1.72 & $\begin{array}{c}1.09- \\
2.71\end{array}$ & $>0.01$ \\
\hline \multicolumn{8}{|l|}{ History of C-section } \\
\hline No & 36 & 1 & - & - & 1 & - & - \\
\hline Yes & 24 & 5.01 & $\begin{array}{l}3.55- \\
7.05\end{array}$ & $>0.01$ & 5.35 & $\begin{array}{l}3.29- \\
7.90\end{array}$ & $>0.01$ \\
\hline \multicolumn{8}{|c|}{ history of preterm delivery } \\
\hline No & 57 & 1 & - & - & 1 & - & - \\
\hline Yes & 6 & 1.64 & $\begin{array}{l}0.81- \\
3.15\end{array}$ & 0.17 & 2.26 & $\begin{array}{l}1.15- \\
4.43\end{array}$ & $>0.01$ \\
\hline \multicolumn{8}{|l|}{$\mathrm{BMI}^{[5]}$} \\
\hline $18.5 \geq$ & 1 & 1 & - & - & 1 & - & - \\
\hline $18.5-25$ & 25 & 3.81 & $\begin{array}{r}0.56- \\
26.81\end{array}$ & 0.16 & 2.42 & $\begin{array}{l}0.33- \\
17.35\end{array}$ & 0.37 \\
\hline $25-30$ & 21 & 3.69 & $\begin{array}{r}0.53- \\
25.65\end{array}$ & 0.18 & 2.11 & $\begin{array}{l}0.30- \\
14.29\end{array}$ & 0.45 \\
\hline $30 \leq$ & 13 & 5.62 & $\begin{array}{r}0.79- \\
39.57\end{array}$ & 0.08 & 3.44 & $\begin{array}{l}0.26- \\
25.59\end{array}$ & 0.22 \\
\hline \multicolumn{8}{|l|}{ Maternal Education } \\
\hline $\begin{array}{l}\text { illiterate / reading and } \\
\text { writing }\end{array}$ & 23 & 1 & - & - & 1 & - & - \\
\hline $\begin{array}{l}\text { secondary } \\
\text { education }\end{array}$ & 10 & 0.51 & $\begin{array}{c}0.26- \\
0.99\end{array}$ & 0.04 & 0.46 & $\begin{array}{c}0.26- \\
0.81\end{array}$ & $>0.01$ \\
\hline high school/ diploma & 14 & 0.66 & $\begin{array}{l}0.27- \\
1.18\end{array}$ & 0.16 & 0.55 & $\begin{array}{l}0.33- \\
0.91\end{array}$ & 0.02 \\
\hline university & 13 & 0.99 & $\begin{array}{l}0.56- \\
1.75\end{array}$ & 0.98 & 0.71 & $\begin{array}{l}0.40- \\
1.26\end{array}$ & 0.24 \\
\hline \multicolumn{8}{|l|}{ Socioeconomic status } \\
\hline good & 34 & 1 & - & - & 1 & - & - \\
\hline low & 26 & 1.78 & $\begin{array}{l}1.15- \\
2.57\end{array}$ & $>0.01$ & 1.65 & $\begin{array}{l}1.07- \\
2.55\end{array}$ & 0.02 \\
\hline
\end{tabular}

Table 5: Unadjusted and adjusted results of Cox regression models for the effect of mental self-rated health during pregnancy on delivery type (Emergency C-section / delivery other) 


\begin{tabular}{|c|c|c|c|c|c|c|c|}
\hline \multirow[t]{2}{*}{ variables } & \multirow[t]{2}{*}{$\mathbf{N}$} & \multicolumn{3}{|c|}{ Univariable } & \multicolumn{3}{|c|}{ Multivariable } \\
\hline & & lative ris] & $95 \% \mathrm{CI}$ & P-value & Relative risk & $95 \% \mathrm{CI}$ & P-value \\
\hline \multicolumn{8}{|c|}{ Maternal self-rated health } \\
\hline good & 27 & 1 & - & - & 1 & - & - \\
\hline bad & 12 & 1.96 & $1.31-2.36$ & 0.02 & 1.91 & $1.04-3.48$ & 0.03 \\
\hline \multicolumn{8}{|c|}{ History of C-section [6] } \\
\hline No & 38 & 1 & - & - & 1 & - & - \\
\hline Yes & 1 & 0.24 & $0.02-1.43$ & 0.11 & 0.21 & $0.003-1.37$ & $>0.10$ \\
\hline \multicolumn{8}{|c|}{ Maternal Age (years) } \\
\hline $16-24$ & 12 & 1 & - & - & 1 & - & - \\
\hline $25-33$ & 19 & 0.96 & $0.49-1.91$ & 0.92 & 0.85 & $0.42-1.71$ & 0.65 \\
\hline $34-42$ & 8 & 1.69 & $0.76-3.77$ & 0.19 & 1.39 & $0.60-3.22$ & 0.43 \\
\hline \multicolumn{8}{|c|}{ Socioeconomic status } \\
\hline good & 23 & 1 & - & - & 1 & - & - \\
\hline low & 16 & 1.72 & $0.94-3.05$ & 0.07 & 1.73 & $0.93-3.23$ & 0.08 \\
\hline
\end{tabular}

[1] Body Mass Index

[2] Cesarean Section

[3] Cesarean Section

[4] Body Mass Index

[5] Body Mass Index

[6] Cesarean Section 